Europe's Journal of Psychology, 7(1), pp. 81-98

www.ejop.org

\title{
Hospital restructuring and downsizing: Effects on nursing staff well-being and perceived hospital functioning
}

\author{
Ronald J. Burke \\ York University
}

Eddy W. S. Ng

Dalhousie University

Jacob Wolpin

Independent Consultant

\begin{abstract}
The health care system, and hospitals, underwent considerable restructuring and downsizing in the early to mid-1900s in several countries as governments cut costs to reduce their budget deficits. Studies of the effects of these efforts on nursing staff and hospital functioning in various countries generally reported negative impacts. Health care restructuring and hospital downsizing was again being implemented in North America in 2009/2010 as governments struggled to once again reduce deficits at a time of worldwide economic recession. This study examines the relationship of downsizing and restructuring efforts with work and well-being outcomes. Data were collected from over 289 nursing staff working in California hospitals in 2009/2010. This research considers the relationship of number of hospital restructuring initiatives reported by nursing staff with indicators of their work satisfaction and psychological well-being and their perceptions of the impact of these initiatives on aspects of hospital performance. Nurses reported a relatively large number of restructuring and downsizing initiatives during the preceding year. Consistent with findings reported over 15 years ago, nursing staff reporting a greater number of restructuring and downsizing initiatives indicated less favorable work and well-being outcomes and more negative effects on hospital functioning. Some suggestions for more successful approaches to cost reductions are offered.
\end{abstract}

Keywords: restructuring, downsizing, hospital, nursing staff, well-being. 
In the early to mid-1990s, the health care sector in several countries engaged in restructuring and downsizing in efforts to contain costs (see McKee, Aiken Rafferty \& Sochalski, 1998; Morey, Fine, Loree, Retzlaff-Roberts \& Tsubakitani, 1992; MullerMundt, 1997; Saltman \& Tigueras, 1998; Sochalski, Aiken \& Fagin, 1997; Tully \& SaintPierre, 1997; White, 1997). Health care is the largest budget item in almost all countries and is projected to increase is size and the population ages. The health care sector, particularly hospitals, became targets for retrenchment. Several studies were undertaken in various countries to determine the effects of hospital restructuring and downsizing on nursing staff -the largest group of employees in health care, patient care -again nurses playing a large role in patient contact, and hospital functioning and performance. Restructuring and downsizing are different though related concepts. It is possible to restructure without downsizing and downsize without restructuring. In most studies they both take place simultaneously (Rondeau \& Wagar, 2003). Restructuring is a planned undertaking in which hospital management rearranges jobs, units and reporting relationships with the goal of reducing costs or increasing efficiency; downsizing involves the reduction of staff to control costs or improve efficiency.

The results of some of these studies (see Aiken \& Fagin, 1997; Aiken, Sochalski \& Anderson, 1996; Armstrong-Stassen, Cameron \& Horsburgh, 1996; Baumann \& Blythe, 2003; Baumann, O'Brien-Pallas, Deber, Donner, Semogas \& Silverman, 1995; Blythe, Baumann \& Giovannetti, 2001; Laschinger, Sabiston, Finegan \& Shamian, 2001; Woodward, Shannon, Cunningham, Mclntosh, Lendrum, Rosenblum \& Brown, 1999) painted a fairly grim picture. Health care restructuring and downsizing was associated with diminished job satisfaction, higher levels of burnout, greater psychological distress, heavier workloads, greater attrition among nursing staff, lower levels of hospital upkeep, lower levels of patient care, and little if any cost savings (Austin, 2007; Shanahan, Brownell \& Roos, 2001; Norrish \& Rundall, 2001).

Nurses are the largest group of employees in the health care system and play an important hands-on role in the delivery of high quality patient care (Aiken, Smith \& Lake, 1994; Institute of Medicine, 2004). Unfortunately, research studies conducted in a number of countries over the past 20 years indicate that nurses are increasingly reporting job dissatisfaction and young women and men are less interested in training to become nursing staff (Aiken, Clarke, Sloane \& Sochalski, 2001). Many countries are now facing shortages of nurses. The nursing profession seems to be in difficulty (Weinberg, 2003; Gordon, 2005).

Now, almost two decades later, the health care sector is again the target of restructuring, downsizing and cost cutting as governments attempt to deal with 
budget shortfalls. In 2009/2010, government leaders were once again facing budget deficits, partly the result of the worldwide economic downturn, and partly the result of escalating costs. Health care costs have not been reduced; in fact they continue to increase at a faster rate than country inflation. Some governments have concluded that they are no longer able to continue to fund healthcare at their current levels. As a consequence, efforts are underway once again to restructure and downsize health care deliver and hospitals.

Will these recent efforts result in the same problems that arose in the 1990s from these efforts? A psychiatrist reportedly once said "Insanity is doing the same thing yet expecting a different result." Will hospital restructuring and downsizing efforts now underway once again fall short in realizing their objectives and produce other undesirable consequences? We consider these questions here.

The present study examines the relationship of hospital restructuring initiatives in $2009 / 2010$ with a variety of individual and unit/hospital outcomes in a sample of nursing staff working in health care settings (hospitals) undergoing significant restructuring and downsizing. The sample worked in hospitals near Los Angeles California, a state undergoing dramatic budget cuts in response to the recent worldwide economic recession. State workers in California have lost their jobs, been required to take unpaid days off work, and hiring freezes have been imposed on all government departments.

The following general hypotheses were considered.

1. Nursing staff indicating fewer restructuring and downsizing initiatives would be more satisfied, more work engaged, less "burned out", less absent, less likely to intend to quit, report fewer psychosomatic symptoms and less medication use.

2. Nursing staff indicating fewer restructuring initiatives would indicate a less negative impact of hospital restructuring and downsizing on hospital functioning, a less negative impact of restructuring and downsizing on hospital impact, and a less negative impact of restructuring and downsizing on their job future security.

These outcome variables were included based on their use in previous hospital restructuring and downsizing research (Burke, 2004; Havlovic, Bouthilete \& van der Wal, 1998; Laschinger, Sabiston, Finegan \& Shamian, 2001). 
Method

Procedure

Data were collected from two sources. First, some data were collected for a hospital located in southern California. The Vice-President of Nursing and Patient Care distributed approximately 300 survey questionnaires to the hospital's staff nurses on behalf of the research team. A $\$ 5$ Starbucks gift cared was offered to the nurse participants. A total of 67 surveys were returned resulting in a response rate of about 22\%. Second, additional data were collected online using Surveymonkey from graduate nursing students. These students had current nursing experience, working either full- or part-time, and were enrolled in a graduate nursing program (a Masters degree) at a large public university. A total of 222 nursing staff enrolled in the Masters program responded to the on-line survey and each respondent also received a $\$ 5$ Starbucks gift card for their participation. The combined sample $(n=289)$ is best described as a convenience sample.

\section{Respondents}

Table 1 presents personal demographic and work situation characteristics of the nursing sample $(n=289)$. The sample was primarily female (92\%), with spouses/partners (73\%), with children (77\%), worked full-time (79\%), had supervisory duties (59\%), had 5 years or more of unit tenure (47\%), 10 years of more of hospital and nursing tenure (44\% and 59\%, respectively), had not changed units in the past year $(90 \%)$, worked in a variety of nursing units, worked in hospitals having 250 or more beds (74\%), worked 35-44 hours per week (66\%), had a Bachelor's of Nursing degree (50\%), and were between 36 and 55 years of age $(60 \%)$.

Table 1. Demographic characteristics of sample

\begin{tabular}{|c|c|c|c|c|c|}
\hline Supervisor duties & $\underline{\%}$ & $\underline{N}$ & $\underline{\text { Unit tenure }}$ & $\underline{\%}$ & $\underline{N}$ \\
\hline$\overline{\text { Yes }}$ & $13 \overline{6}$ & $5 \overline{9} .4$ & less than 4 years & 106 & $\overline{46} .3$ \\
\hline \multirow[t]{2}{*}{ No } & 93 & 40.6 & $4-5$ years & 16 & 7.0 \\
\hline & & & More than 5 years & 107 & 46.7 \\
\hline \multicolumn{6}{|l|}{ Hospital tenure } \\
\hline 3 years or less & 59 & 25.8 & Nursing tenure & & \\
\hline $3-5$ years & 31 & 13.5 & 3 years or less & 37 & 16.3 \\
\hline $5-10$ years & 38 & 13.6 & 3-5 years & 19 & 8.4 \\
\hline \multirow[t]{2}{*}{10 years or more } & 101 & 44.1 & 5-10 years & 37 & 16.3 \\
\hline & & & 10 years or more & 134 & 59.0 \\
\hline \multicolumn{6}{|l|}{ Work status } \\
\hline$\overline{\text { Full-time }}$ & 180 & 78.9 & Nursing unit & & \\
\hline Part-time & 48 & 21.1 & Administration & 27 & 11.8 \\
\hline
\end{tabular}




\begin{tabular}{|c|c|c|c|c|c|}
\hline & & & Education & 24 & 10.5 \\
\hline Changed units last & year & & Emergency & 27 & 11.8 \\
\hline Yes & 24 & 10.5 & Intensive care & 39 & 17.1 \\
\hline No & 205 & 89.5 & Medical/surgical & 21 & 9.1 \\
\hline & & & Neonatal & 20 & 8.6 \\
\hline Hospital size & & & Obstetrics & 21 & 9.1 \\
\hline 400 beds or more & 83 & 36.9 & Telemetry & 20 & 8.6 \\
\hline $251-400$ & 84 & 37.3 & & & \\
\hline $151-250$ & 29 & 12.9 & & & \\
\hline 34 or less & 44 & 19.4 & Gender & & \\
\hline & & & $\overline{\text { Male }}$ & 17 & 7.5 \\
\hline & & & Female & 211 & 92.5 \\
\hline Hours worked & & & & & \\
\hline 34 or less & 44 & 19.4 & & & \\
\hline $35-39$ & 73 & 32.2 & & & \\
\hline $40-44$ & 63 & 27.8 & & & \\
\hline 45 or more & 47 & 20.7 & & & \\
\hline & & & Age & & \\
\hline Education & & & Under 35 & 52 & 23.3 \\
\hline $\mathrm{RN}$ & 65 & 28.4 & $36-45$ & 54 & 24.2 \\
\hline BA-Nursing & 116 & 50.7 & $46-55$ & 79 & 35.4 \\
\hline MA-Nursing & 46 & 20.1 & 56 and older & 38 & 17.0 \\
\hline PhD Nursing & 2 & 0.9 & & & \\
\hline & & & Parental status & & \\
\hline Marital status & & & Children & 177 & 77.0 \\
\hline Married/cohabiting & 167 & 72.9 & No children & 53 & 23.0 \\
\hline Single & 62 & 27.1 & & & \\
\hline
\end{tabular}

\section{Measures}

Restructuring initiatives

Nursing staff were presented with a list of 16 potential restructuring initiatives (see Table 2) and asked whether each had been implemented in their hospitals during the preceding year (1=yes, $2=n o)$. Respondents indicated that an average of 10.1 restructuring initiatives had been implemented; a Canadian nursing sample indicated an average of 9.6 being implemented in the past year (Burke \& Greenglass, 2001) Thus considerable restructuring initiatives were being undertaken by their hospitals.

\section{Work outcomes}

Three work outcomes were included. Job satisfaction was measured by a 5-item scale (alpha=.87) developed by Quinn and Shepard (1974). One item was "All in all, how satisfied would you say you are with your job? (1=very satisfied, 4=not at all satisfied). Absenteeism was measured by two items (alpha=.76). "How many days of scheduled work have you missed in the past month?" (1=none, 4=three or more days). Intent to quit was measured by a single item. "Taking everything into account 
how likely is it that you will make a genuine effort to find a new job with another employer within the next 12 months?" (1=very likely, 3=not at all likely).

\section{Work engagement}

Three dimensions of work engagement were included using measures developed by Schaufeli and Bakker (2003). Vigor was assessed by 6 items (alpha=.81) A sample item was "At my work, I feel that I am bursting with energy." Dedication was assessed by 5 items (alpha=.89). One item was "My job inspires me." Finally, Absorption was measured by 6 items (alpha=.84). One item was "I get carried away when I'm working." The reliabilities of these measures was typical of those reported by others (see Bakker \& Leiter, 2010). The three measures of work engagement were significantly and positively inter-correlated, the mean inter-correlation being .54 $(p<.001)$.This value was consistent with most of the inter-correlations previously reported (Bakker \& Leiter, 2010). In keeping with common practice, each work engagement measures was considered separately.

\section{Burnout}

Three dimensions of burnout were considered, each measured by the Maslach Burnout Inventory (MBI) developed by Maslach, Jackson and Leiter (1996) Respondents indicated how often they experienced particular feelings on a 7-point scale $(0=$ never, $6=$ every day). Emotional exhaustion was measured by a 5 -item scale (alpha=.91). An item was "I feel emotionally drained from my work". Cynicism was assessed by a 5-item scale (alpha=.88). One item was "I have become more cynical about whether my work contributes anything." Professional efficacy was measured by a 6-item scale (alpha=.82). A sample item was "at my work, I feel confident that I am effective at getting things done." The three measures of burnout were significantly inter-correlated. Exhaustion and cynicism correlated .62 ( $p<.001)$ and Efficacy was negatively correlated with both Cynicism and Exhaustion ( $r s=-.40$ and $.15, \mathrm{p}<.001$ and .05 , respectively). These values were consistent with most of the previously reported inter-correlations (Maslach, Jackson \& Leiter, 1996), and were considered separately here.

\section{Psychological well-being}

Two aspects of psychological well-being were included. Psychosomatic symptoms were measured using a 30-item scale (alpha=.92) developed by Derogatis, Lipman, Rickels, Uhlenhuth and Covi (1974). Respondents indicated on a 4-point scale (1=never, 4=extremely often) how often they experienced particular symptoms during the past three months (e.g., headaches, poor appetite, pain in the lower part of you back, faintness or dizziness). Medication use was measured by 5 items (alpha=.62). Respondents indicated how often they took each medication ( 1 =never, 
$5=a$ lot). Items included pain medication, sleeping pills, and tranquilizers such as valium.

Hospital-based measures

Three hospital-based measures were included. Impact of restructuring on hospital functioning was measured by 7 items (alpha=.94). Respondents indicated their agreement with each item indicating their views on the effects of restructuring and budget cuts using a 5 point Likert scale (1=strongly disagree, 3=neutral, 5=strongly agree). Items included "Lowered the quality of health care provided to our patients" and "Required nursing staff to perform more maintenance/housekeeping duties". Impact on hospital facilities was measured by an 8 item scale (alpha=.92). Respondents indicated the extent of changes in their hospital during the past year (1=gotten worse, 3=about the same; 5=improved). Items included "level of cleanliness", and "repairs to hospital buildings". Impact on future job security was measured by 7 items (alpha=.84). Respondents indicated their views on the likelihood of particular work events or actions happening to them on a 4 point scale ( $1=$ highly unlikely, 4=almost certain. Items included layoff, demotion, and change in employment status to part-time.

Results

Descriptive statistics

Table 2 shows the number and percentage of nursing staff reporting that each of the 16 restructuring initiatives (alpha=.82) had been implemented in the past year. The most common were: budget cuts (83\%), a hiring freeze (77\%), overtime restrictions (74\%), not filling job vacancies (64\%), and a wage freeze (45\%)

Table 2. Restructuring Initiatives

$\begin{array}{lrc}\text { Restructuring initiatives } & \underline{\mathrm{N}} & \underline{\%} \\ \text { Staff layoffs } & 82 & 33.2 \\ \text { Beds closed } & 83 & 33.7 \\ \text { Units closed } & 81 & 32.9 \\ \text { Wage freeze } & 110 & 44.9 \\ \text { Hiring freeze } & 190 & 76.9 \\ \text { Wage rollback } & 31 & 12.6 \\ \text { Budget cuts } & 204 & 82.6 \\ \text { Early retirement incentives } & 79 & 32.4 \\ \text { Job sharing } & 50 & 20.4 \\ \text { Switch to part-time } & 57 & 23.3\end{array}$


Overtime restrictions

Shortened work week

Shortened work year

Not filling job vacancies

Staff bumping

Discontinuing specialty services
181

29

21

156

42

76
73.6

11.8

8.5

63.7

31.0

\section{Analysis plan}

Hierarchical regression analyses were undertaken with predictor variables entered in particular blocks. The first block of predictors were personal demographics $(n=5)$ which included, age, level of education, and marital status. The second block of predictors included work situation characteristics $(n=5)$ such as supervisory responsibilities, hospital size, and nursing unit tenure. The third block of predictors included the measure of restructuring initiatives, the main variable of interest. When a block of predictors accounted for a significant amount or increment in explained variance on a given outcome measures $(p<.05)$, individual items or measures within such blocks having significant and independent relationships with this outcome were then identified $(P<.05)$. This approach to analysis shows the relationship of the work experiences with a given outcome controlling for the effects of both individual personal demographics and work situation characteristics.

Restructuring initiatives and work attitudes and behaviors

Table 3 shows the results of hierarchical regression analyses in which various work outcomes were regressed on the three blocks of predictors. The following comments are offered in summary.

Table 3. Restructuring Initiatives and Work Outcomes

$\underline{\text { Work Outcomes }}$

Work Engagement

Vigor ( $\mathrm{N}=-200)$

Personal demographics

Work situation characteristics

Restructuring initiatives (-.16)

Dedication ( $\mathrm{N}=202$ )

Personal demographics

Work situation characteristics

Restructuring initiatives (-.16)

Absorption ( $\mathrm{N}=197$ )

Personal demographics

Work situation characteristics

Restructuring initiatives
$\underline{R} \quad \underline{R}$ Change R2 $\quad \underline{P}$

$\begin{array}{llll}.18 & .03 & .03 & \text { NS }\end{array}$

$\begin{array}{llll}.23 & .05 & .02 & \text { NS }\end{array}$

$\begin{array}{llll}.27 & .08 & .03 & .05\end{array}$

$\begin{array}{llll}.12 & .01 & .01 & \text { NS }\end{array}$

$\begin{array}{llll}.20 & .04 & .03 & \text { NS }\end{array}$

$\begin{array}{llll}.25 & .06 & .02 & .05\end{array}$

$\begin{array}{llll}.22 & .05 & .05 & \text { NS }\end{array}$

$\begin{array}{llll}.26 & .07 & .02 & \text { NS }\end{array}$

$\begin{array}{llll}.27 & .07 & .00 & \text { NS }\end{array}$ 


\section{Burnout}

Exhaustion ( $\mathrm{N}=203$ )

Personal demographics

Work situation characteristics

Restructuring initiatives (.22)

.28

.33

.08

.08

.01

.39

.11

.03

NS

.01

Cynicism ( $\mathrm{N}=202$ )

Personal demographics

$.22 \quad .05$

.04

Work situation characteristics

Restructuring initiatives (.24)

.30

.09

.05

NS

.38

.15

.04

NS

.001

Efficacy ( $\mathrm{N}=199)$

Personal demographics

Work situation characteristics

Supervisor duties (.21)

Restructuring initiatives

.10

.26

$.01 \quad .01$

NS

$\begin{array}{lll}.26 & .07 & .06\end{array}$

.05

$\begin{array}{llll}.28 & .08 & .01 & \text { NS }\end{array}$

Job Satisfaction ( $\mathrm{N}=193$ )

Personal demographics

Work situation characteristics

Supervisor duties (.20)

Changed units (.176)

Unit tenure (-.17)

Restructuring initiatives (-.22)

$\begin{array}{llll}.41 & .17 & .05 & .01\end{array}$

Absenteeism ( $\mathrm{N}=196)$

Personal demographics

$.18 \quad .03$

.03

NS

Work situation characteristics

Restructuring initiatives

.20

.04

.01

NS

$\begin{array}{llll}.20 & .04 & .00 & \text { NS }\end{array}$

Intent to Quit ( $N=202$ )

Personal demographics

Work situation characteristics

Supervisor duties (-.16)

Restructuring initiatives (.27)

$\begin{array}{llll}.19 & .04 & .04 & \text { NS } \\ .32 & .10 & .06 & .05 \\ & & & \\ .41 & .17 & .07 & .001\end{array}$

Work engagement. Nursing staff reporting a greater number of restructuring initiatives also indicated lower levels of both Vigor and Dedication (Bs=-.16 and -.16, respectively). Number of restructuring initiatives had no relationship with Absorption.

Burnout. Nursing staff indicating a greater number of restructuring initiatives also reported higher levels of burnout. Thus nurses indicating more restructuring initiatives also reported higher levels of Exhaustion and Cynicism and lower levels of Efficacy $(\mathrm{Bs}=.22, .24$ and -.21$)$.

Job satisfaction. Nursing staff reporting a greater number of restructuring initiatives also indicated lower levels of job satisfaction $(B=-.22)$. 
Absenteeism. Restructuring initiatives had no relationship with self-reported absenteeism. Absenteeism is likely affected by a number of factors, hospital restructuring initiatives being only one of these.

Intent to quit. Nursing staff reporting a larger number of restructuring initiatives also indicated greater intention to quit $(B=.27)$.

Restructuring initiatives and Psychological health

Table 4 shows the results of hierarchical regression analyses in which two measures of psychological health were separately regressed on the three blocks of predictors. Nursing staff reporting a greater number of restructuring initiatives also indicated more psychosomatic symptoms $(B=.24)$. Number of restructuring initiatives had no relationship with medication usage. Medicine use is likely affected by a number of factors, hospital restructuring being only one of these.

Table 4. Restructuring Initiatives and Psychological Well-Being

\begin{tabular}{|c|c|c|c|c|}
\hline Psychological Well-Being & $\underline{\mathrm{R}}$ & $\underline{\mathrm{R} 2}$ & Change R2 & \\
\hline \multicolumn{5}{|l|}{ Psychosomatic Symptoms ( $N=184)$} \\
\hline Personal demographics & .24 & .06 & .06 & NS \\
\hline Work situation characteristics & .30 & .09 & .03 & NS \\
\hline Restructuring initiatives (.24) & .37 & .14 & .05 & .01 \\
\hline \multicolumn{5}{|l|}{ Medication use $(\mathrm{N}=200)$} \\
\hline Personal demographics & .23 & .05 & .05 & NS \\
\hline Work situation characteristics & .26 & .07 & .02 & $N$ \\
\hline Restructuring initiatives & .27 & .07 & .00 & NS \\
\hline
\end{tabular}

Restructuring initiatives and hospital-level outcomes

Table 5 presents the results of hierarchical regression analyses in which three hospitallevel impacts of restructuring were separately regressed on the three blocks of predictors. The following comments are offered in summary. Restructuring initiatives accounted for a significant increase in explained variance in all three analyses. Nursing staff reporting more restructuring initiatives in the past year also indicated a more negative impact of these on hospital function and effectiveness $(B=-.30)$, lower levels of hospital upkeep $(B=-.23)$, and greater threats to job security $(B=.42)$. 
Table 5. Restructuring Initiatives and Perceptions of Hospital functioning

\begin{tabular}{|c|c|c|c|c|}
\hline $\begin{array}{l}\text { Perceptions of } \\
\text { Hospital Functioning } \\
\text { Hospital Upkeep }(\mathrm{N}=202)\end{array}$ & $\underline{R}$ & $\underline{\mathrm{R} 2}$ & Change R2 & $\underline{P}$ \\
\hline Personal demographics & .14 & .02 & .02 & NS \\
\hline $\begin{array}{l}\text { Work situation characteristics } \\
\text { Supervisory duties (-..18) } \\
\text { Changed units (-.15) } \\
\text { Hospital size (-.14) }\end{array}$ & .28 & .08 & .06 & .05 \\
\hline Restructuring initiatives $(-.23)$ & .36 & .13 & .05 & .001 \\
\hline Impact on Hospital ( $\mathrm{N}=198$ ) & & & & \\
\hline $\begin{array}{l}\text { Personal demographics } \\
\text { Age (-123) }\end{array}$ & .34 & .12 & .12 & \\
\hline $\begin{array}{l}\text { Work situation characteristics } \\
\text { Supervisor duties (.16) } \\
\text { Hospital size (.21) }\end{array}$ & .44 & .19 & .07 & .01 \\
\hline Restructuring initiatives (.30) & .52 & .27 & .08 & .001 \\
\hline Threats to security ( $N=202$ ) & & & & \\
\hline Personal demographics & .13 & .02 & .02 & NS \\
\hline Work situation characteristics & .25 & .06 & .04 & NS \\
\hline Restructuring initiatives (.42) & .47 & .22 & .16 & .001 \\
\hline
\end{tabular}

Two observations are worth noting. First, restructuring initiatives accounted for a greater increment in explained variance on every outcome measure than did personal demographic factors and work situation characteristics. Second, restructuring initiatives were found to predict work outcomes, an indicator of psychological well-being, and nursing staff perceptions of hospital functioning.

\section{Discussion}

The results presented here (see Tables 3, 4 and 5) were consistent with previously reported findings on health care and hospital restructuring and downsizing in many areas (Aiken, Sochalski \& Anderson, 1996; Baumann, O'Brien-Pallas, Deber, Donner, Semogas \& Silverman, 1999; Richard Ivey School of Business, 1997; Shanahan, Brownell \& Roos, 2001; Sochalski, Aiken \& Fagin, 1997; Woodward, Shannon, Cunningham, Mclntosh, Lendrum, Rosenblum \& Brown, 1999). In addition they support conclusions of studies of downsizing carried out in the private sector (Burke \& Nelson, 1998, 1997; Cameron, 1994; Cameron, Freeman \& Mishra, 1991; Cascio, 2002, 1998, 1993; Gowing, Kraft \& Quick, 1998; Ludy, 2009; Noer, 1993; O'Neill \& Lenn, 1995).

Hospitals undertook a number of initiatives in their restructuring and downsizing efforts (see Table 2). Nursing staff reporting a greater number of hospital restructuring 
initiatives were also less job satisfied, less work engaged, more "burned out", and more likely to intend to quit (Table 3). Nursing staff indicating a greater number of restructuring and downsizing initiatives also self-reported a greater number of psychosomatic symptoms (see Table 4) And nursing staff reporting a greater number of restructuring and cost-cutting initiatives perceived a more negative impact of these on hospital functioning, level of hospital maintenance and upkeep, and threats to future job security (see Table 5).Thus the results obtained here provided general support for the two comprehensive hypotheses that guided the research.

These findings suggest an urgent need for more effective hospital responses to financial restraint pressures they are now facing. Fortunately more effective alternatives have been proposed, many of these resulting from the first round of hospital restructurings and downsizings that took place almost 20 years ago.

Nursing staff working in hospitals that underwent restructuring and downsizing commonly describe the process as unilateral and top-down, little information is provided to them, feelings of insecurity are heightened, and higher levels of workload are commonly reported (Baumann, O'Brien-Pallas, Deber, Donner, Semogas \& Silverman, 1995; Richard Ivey School of Business, 1997)

Here are some suggestions supported by the research findings that are likely to address common nursing staff reactions to restructuring and downsizing processes.

1. Hospitals must develop a clear purpose of what they would like to accomplish and why (their motives). Hospitals must approach this in an open, honest and fully transparent way.

2. Hospitals must make a commitment to long term efforts to address their situations; there is no quick fix.

3. Hospital and nursing leadership must be visible and available.

4. Hospitals must make resources (time and money) available during this period of transition.

5. Transition efforts must be undertaken in cooperation with the relevant nursing associations.

6. Restructuring efforts must be a collaborative effort in which ownership, responsibility and accountability is widely shared.

7. Staff terminations should be undertaken only as a last resort if other initiatives do not produce desired outcomes. Instead all staff should be invited to offer suggestions on ways to cut costs and reduce waste

8. Data needs to be collected throughout the hospital to determine what is working and what is not working. 
9. There is a need to release negative reactions to whatever is being changed grieving the loss of the past.

10. Trust of senior hospital management needs to be re-established and strengthened.

11. There is a need for communication, lots of it, using various media with some repetition. Person contact- one-to-one, and in work teams is vital.

12. Patient care must remain as the paramount goal throughout the transition process.

13. Hospital and nursing leadership need to plan for the change initiatives prior to their implementation, plan for the implementation and monitoring of these efforts, and plan for recovery and revitalization efforts following the restructuring initiatives being undertaken.

\section{Implications}

Research on the success of organizational restructuring, downsizing and cost-cutting carried out in both the private sector and the health care sector has highlighted the generally low levels of success in these efforts, approaches that were dysfunctional and efforts that seemed to work (see Ludy, 2009; Cascio 2002; Cameron, 1994).The present study, conducted almost two decades later, showed the same pattern of results. It is clear that approaching these complex and difficulty transitions in the same ways tried two decades ago will not work well. It appears that relatively little if anything has been learned by hospitals, and the health care system more generally, from the large amount of previous work on hospital restructuring and downsizing. Undertaking the same processes will generate the same negative results as this study has shown.. Hopefully hospital executives and senior nursing leadership will not make use of approaches that proved to be ineffective effective in the past but instead experiment with other strategies and processes (Ludy, 2009)

Seminars for hospital administrators and nursing managers that address hospital restructuring and downsizing processes appear to be a worthwhile undertaking. There is considerable academic research and writing on this topic, some hospital case studies are available, and there is likely to be considerable knowledge present among any administrators and nursing staff managers that might attend. .

\section{Research limitations}

Some limitations of the present study should be noted to put the findings into a larger context. First, the sample, while relatively large, was a convenience sample and not 
necessarily representative of all nursing staff in California. Second, all data were collected using self-report questionnaires raising the possibility that nursing responses were a function of common method variance. Third, questions of causality cannot be addressed since all data were collected at only one point in time. Fourth, many of the work and health outcomes were themselves moderately inter-correlated.

\section{Future research directions}

Given the likelihood of more widespread healthcare and hospital restructuring and downsizing, this area offers many interesting research possibilities. First, additional studies using larger and more representative samples need to be undertaken to document the potential effects of these efforts on nursing staff, patient care, and hospital functioning. Second, greater attentions needs to be paid to understand particular downsizing and restructuring processes and why these were undertaken by specific hospitals. Third, longitudinal studies are needed to determine causal relationships between restructuring efforts, both the number of initiatives undertaken and how these are implemented, and relevant outcome measures. Fourth, evaluation studies of various approaches to the implementation of restructuring and cost cutting need to be undertaken to sort out which approaches seem to be working and which approaches seem to be falling short. These studies should ideally include independent and objective assessments of relevant outcomes such as staff turnover and absenteeism, quality of patient care, and costs. Fifth, research on attempts to make the available research evidence available to practitioners, what works and what works less well, might limit the further use of restructuring and downsizing processes that have been shown to have limited effectiveness.

\section{Acknowledgements}

Preparation of this manuscript was supported in part by York University, the School of Business, Dalhousie University and the California State Polytechnic University -Pomona. We thank our respondents for their participation in the research.

\section{References}

Aiken, L. H., \& Fagin, C. M. (1997). Evaluating the consequences of hospital restructuring. Medical Care, 35, 1-4.

Aiken, L. H., Sochalski, J., \& Anderson, G.F. (1996) Downsizing the hospital nursing workforce. Health Affairs, 15, 88-92.

Aiken, L.H., Smith, H. L.., \& Lake, E. T (1994). Lower medicare mortality among a set of hospitals known for good nursing care. Medical Care, 32, 771-787. 
Aiken, L. H., Clarke, S. P., Sloane, D. M., \& Sochalski, J. A. (2001). An international perspective on hospital nurses' work environments: The case for reform. Policy, Politics and Nursing, 2, 255-263.

Armstrong-Stassen, M., Cameron, S. J., \& Horsburgh, M. E. (1996). The impact of organizational downsizing on the job satisfaction of nurses. Canadian Journal of Nursing Administration, 9, 8-32.

Austin, W. (2007). The McDonaldization of nursing. Health, 11, 265-268.

Bakker, A. B., \& Leiter, M. P. (2010). Work engagement: A handbook of essential theory and research. New York: Psychology Press.

Baumann, A., \& Blythe, J. (2003). Restructuring, reconsidering, reconstructing: Implications for health human resources. International Journal of Public Administration, 26, 1561-1580.

Baumann, A., O'Brien-Pallas, L., Deber, R., Donner, G., Semogas, D., \& Silverman, B. (1995). The process of downsizing in selected Ontario acute care hospitals: budget reduction strategies and planning process. Toronto: Quality of Nursing Worklife Research Unit, University of Toronto.

Blythe, J., Baumann , A., \& Giovannetti, P. (2001). Nurses' experiences of restructuring in three Ontario hospitals. Journal of Nursing Scholarship, 33, 61-68.

Burke, R. J. (2004). Implementation of hospital restructuring and nursing staff perceptions of hospital functioning. Journal of Health Organization and Management, 18, 279-289.

Burke, R. J., \& Greenglass, E. R. (2001). Hospital restructuring and nursing staff well-being: The role of perceived hospital and union support. Anxiety, Stress, and Coping, 14, 93-115.

Burke, R. J., \& Nelson, D. L. (1998). Downsizing, restructuring and privatization: A North American perspective. In M. K. Gowing, J. D. Kraft \& J. C. Quick (eds.), The new organizational reality: Downsizing, restructuring and revitalization. Washington, D. C.: American Psychological Association, pp. 21-54.

Burke, R. J., \& Nelson, D. L. (1997). Downsizing and restructuring: Lessons from the firing line for revitalizing organizations. Leadership and Organizational Development Journal, 18, 32-334.

Cameron, K. (1994). Strategies for successful organizational downsizing. Human Resources Management, 33, 189-221. 
Cameron, K., Freeman, S. J., Mishra, A. K. (1991). Best practices in white-collar downsizing: Managing contradictions. Academy of Management Executive, 5, 57-73.

Cascio, W. F. (2002). Responsible restructuring: Creative and profitable alternatives to layoffs. San Francisco: Berrett0-Koehler.

Cascio, W. F, (1998). Learning from outcomes: Financial experiences from 311 firms that have downsized. In M. K. Gowing, J. D. Kraft \& J. C Quick (eds.) The new organizational reality: Downsizing, restructuring and revitalization. Washington, D. C.: American Psychological Association. pp. 55-70.

Cascio, W. F. (1993 Downsizing: What do we know? What have we learned? Academy of Management Executive, 7, 95-104.

Derogatis, L. R, Lipman, R. S., Rickels, R. S., Uhlenhuth, E. H., \& Covi, L. (1974). The Hopkins Symptom Checklist (HSCL): A self-report symptom inventory. Behavioral Science, 19, 1-15.

Gordon, S. (2005). Nursing against the odds: How health care cost cutting, media stereotypes and medical hubris undermine nurses and patient care. Ithaca, NY: Cornell University Press.

Gowing, M. K., Kraft, J. D., \& Quick, J. C. (1998). The new organizational reality: downsizing, restructuring and revitalization. Washington, D. C: American Psychological Association.

Havlovic, S. J., Bouthillete, E., \& van der Wal, R. (1998). Coping with downsizing and job loss: Lessons from the Shaughnessy Hospital closure. Canadian Journal of Administrative Sciences, 15, 325-332.

Institute of Medicine (2004). Keeping patients safe: Transforming the work environment of nurses. Washington, DC: National Academies Press.

Laschinger, .H K. S., Sabiston, J.A., . Finegan, J., Shamian, J. (2001). Voices from the trenches: Nurses' experiences of hospital restructuring in Ontario. Canadian Journal of Nursing Leadership, 14, 6-13.

Ludy, P. J. (2009). Profit building: Cutting costs without cutting people. San Francisco: Berrett-Koehler.

Maslach, C., Jackson, S. E., \& Leiter, M. P. (1996). The Maslach Burnout Inventory. 3rd ed. Consulting Psychologists Press. Palo Alto, CA. 
McKee, M., Aiken, L., Rafferty, A. M., \& Sochalski, J. (1998). Organizational change and quality of health care: An evolving international agenda. Quality in Health Care, 7, 3741.

Morey, R. C., Fine, D. J., Loree, S., W., Retzlaff-Roberts, D. L, \& Tsubakitani, S. (1992). The trade-off between hospital cost and quality of care. Medical Care, 30, 677-698.

Muller-Mundt, G. (1997). Trends in hospital restructuring and the impact on the workforce in Germany. Medical Care, 35, 132-142.

Noer, D. (1993). Healing the wounds: Overcoming the trauma of layoffs and revitalizing downsized organizations. San Francisco: Jossey-Bass.

Norrish, B. R., \& Rundall, T. G. (2001). Hospital restructuring and the work of registered nurses. Milbank Quarterly, 79, 55-79.

O'Neill, H. M., \& Lenn, J. (1995). Voices of survivors: Words that downsizing CEOs should hear. Academy of Management Executive, 9, 23-34.

Quinn, R. P., \& Shepard, L. J. (1974). The 1972-73 Quality of Employment Survey. Institute for Social Research. University of Michigan, Ann Arbor, MI.

Richard Ivey School of Business (1997). Leading the management of change: A study of 12 Ontario hospitals. London, ON: Richard Ivey School of Business.

Rondeau, K. V., \& Wagar, T. H. (2003). Downsizing and organizational restructuring: What is the impact on hospital performance? International Journal of Public Administration, 26, 1647-1668.

Saltman, R. B., \& Tigueras, J. (1998). Analyzing the evidence on European health care reforms. Health Affairs, 17, 85-108.

Schaufeli, W. B.\& Bakker, A. B. (2003). Utrecht Work Engagement Scale: Preliminary Manual. Department of Psychology, Utrecht University, the Netherlands.

Shanahan, M., Brownell, M. D. \& Roos, N. P. (2001). The unintended and unexpected impact of downsizing: Costly hospitals become more costly. Medical Care, 37,123-134.

Sochalski, J., Aiken, L. H., \& Fagin, C. M. (1997). Hospital restructuring in the United States, Canada, and Western Europe: An outcomes research agenda. Medical Care, 3, 13-25. 
Tully, P., \& Saint-Pierre, E. (1997). Downsizing Canada's hospitals: 1986/87 to 1994/95. Health Reports, 8, 33-39.

Weinberg, D. D. (2003). Code Green: Money-drivenf hospitals and the dismantling of nursing. Ithaca, NY: Cornell University Press.

White, K. (1997). Hospital restructuring in North American and Europe. Medical Care, 35, 7-112.

Woodward, C. A., Shannon, H.; S., Cunningham, C., Mclntosh, J., Lendrum, B., Rosenblum, D. \& Brown, J. (1999). The impact of re-engineering and other cost reduction strategies on the staff of a large teaching hospital. Medical Care, 37, 556-569

\section{About the authors:}

Ronald J. Burke is Emeritus Professor of Organizational Behavior, Schulich School of business, York University in Toronto. His current interests include crime and corruption in organizations, health and safety, corporate reputation, and work and health.

Address for correspondence: Prof. Ronald Burke, Schulich School of Business, York University, 4700 Keele St. Toronto, ON M3J 1P3, Canada

E-mail: rburke@schulich.yorku.ca

Eddy $\mathrm{Ng}$ is currently Associate Professor of Organizational Behavior, School of Business, Dalhousie UNiversity in Halifax. His research considers diversity in organizaitns, job anc career experiences of recent university graduates, and business students attitudes towards social responsibility.

E-mail: edng@dal.ca

Jacob Wolpin is an independent consultant working in Toronto. His current projects involve studying effects of an aging workforce, and efforts to improve human resource management in the public sector.

E-mail: jwolpin@schulich.yorku.ca 